
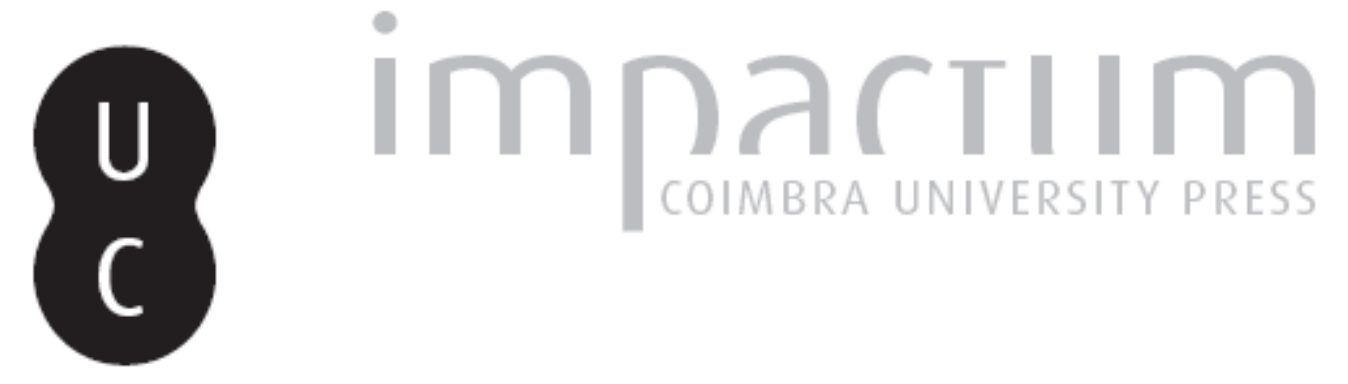

\title{
[Recensão a] COELHO, Maria Helena da Cruz - O Município de Coimbra. Monumentos Fundacionais
}

Autor(es): $\quad$ Santos, Maria José Azevedo

Publicado por: Centro de História da Sociedade e da Cultura

URL persistente:

URI:http://hdl.handle.net/10316.2/39403

DOI:

DOI:http://dx.doi.org/10.14195/1645-2259_13_21

Accessed : $\quad$ 26-Apr-2023 12:43:20

A navegação consulta e descarregamento dos títulos inseridos nas Bibliotecas Digitais UC Digitalis, UC Pombalina e UC Impactum, pressupõem a aceitação plena e sem reservas dos Termos e Condições de Uso destas Bibliotecas Digitais, disponíveis em https://digitalis.uc.pt/pt-pt/termos.

Conforme exposto nos referidos Termos e Condições de Uso, o descarregamento de títulos de acesso restrito requer uma licença válida de autorização devendo o utilizador aceder ao(s) documento(s) a partir de um endereço de IP da instituição detentora da supramencionada licença.

Ao utilizador é apenas permitido o descarregamento para uso pessoal, pelo que o emprego do(s) título(s) descarregado(s) para outro fim, designadamente comercial, carece de autorização do respetivo autor ou editor da obra.

Na medida em que todas as obras da UC Digitalis se encontram protegidas pelo Código do Direito de Autor e Direitos Conexos e demais legislação aplicável, toda a cópia, parcial ou total, deste documento, nos casos em que é legalmente admitida, deverá conter ou fazer-se acompanhar por este aviso.

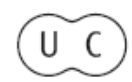



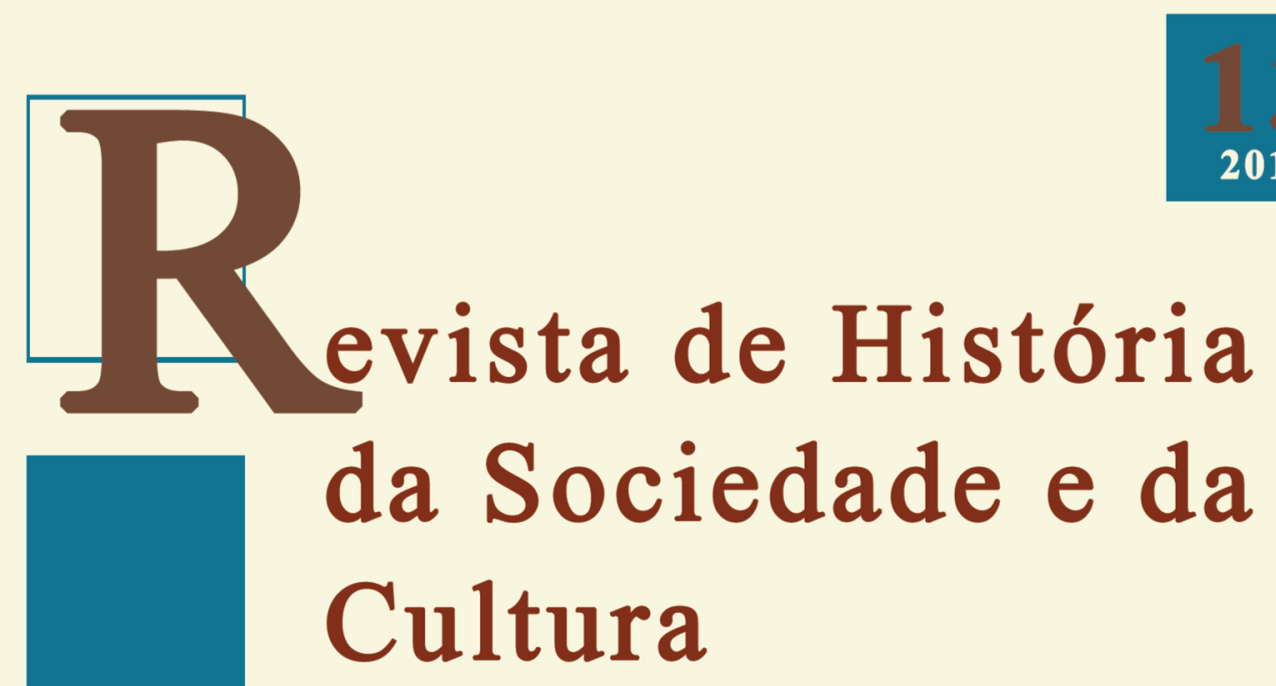

2013

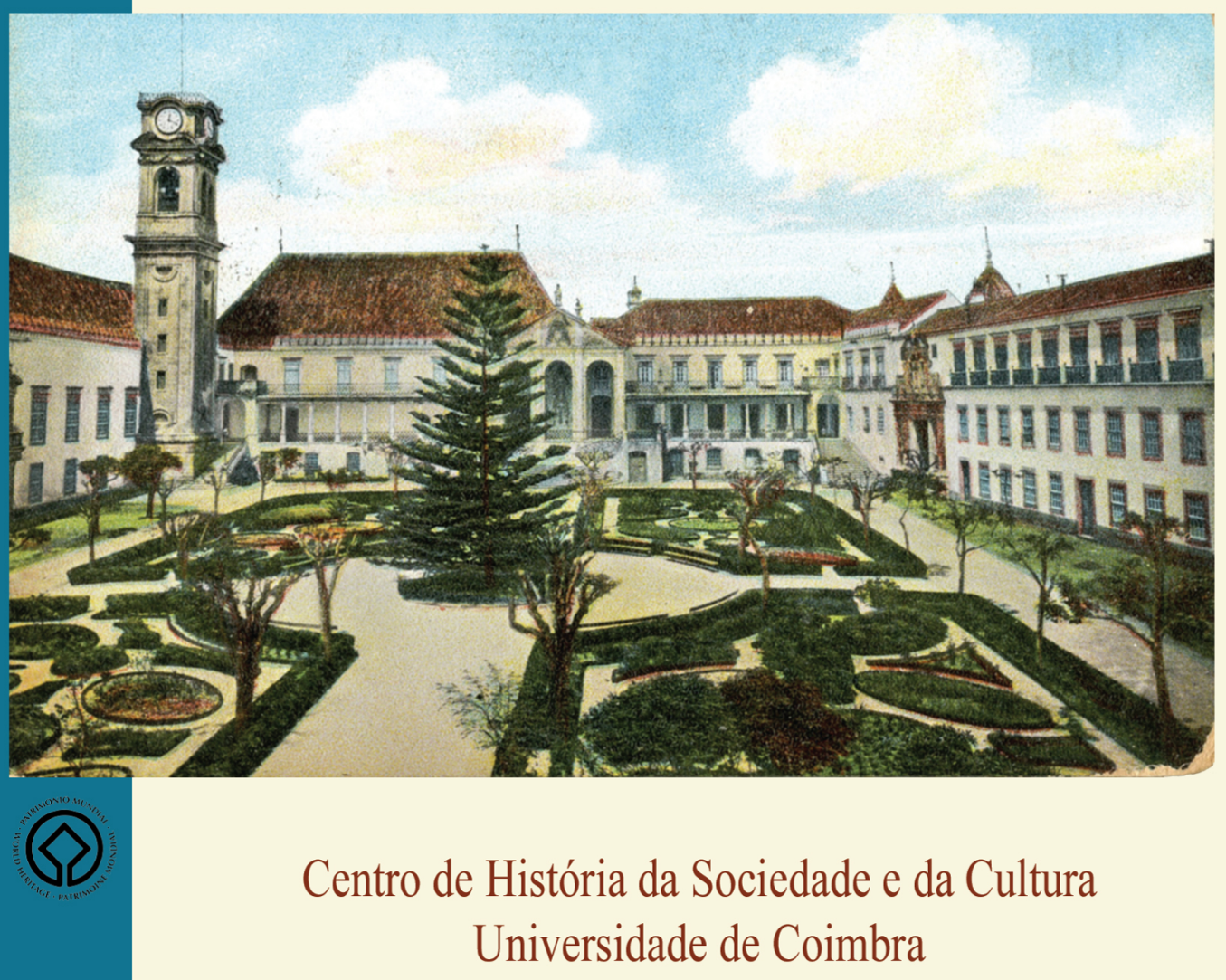

Coimbra 
Congresso, em estreia mundial, pela Orquestra Clássica do Centro e pelo Coro, hoje designado Inês de Castro, no dia 28 de Março, na Sé Nova de Coimbra.

Por tudo o que fica dito, o Congresso em apreço e a prova escrita, agora editada, contribuem para enriquecer a historiografia inesiana ao mesmo tempo que lançam sementes para o cultivo de novas espécies histórico-científicas e culturais sobre Pedro e Inês.

\section{Maria José Azevedo Santos}

Universidade de Coimbra e Centro de História da Sociedade e da Cultura da Universidade de Coimbra mazevedo_santos@yahoo.com

\section{COElHo, Maria Helena da Cruz - O Município de Coimbra. Monumentos Fundacionais. Promoção e Direcção do Projecto: Maria José Azevedo Santos. Editores: Câmara Municipal de Coimbra e Imprensa da Universidade de Coimbra, Coimbra, 2013, 258 págs.}

Coimbra celebrou, em 2011, 900 anos do foral outorgado aos habitantes da cidade, pelo Conde D. Henrique e D. Teresa, no dia 26 de Maio de 1111. Disso dá testemunho verdadeiro um "pedaço" de bom pergaminho de coiro, original, em visigótica de transição para a carolina, do presbítero D. Telo, conservado no Arquivo Nacional da Torre do Tombo. Entretanto, o pelouro da cultura da Câmara Municipal tomou este aniversário como argumento feliz para conceber uma programação científico-cultural exigente, criativa e interdisciplinar. ${ }^{1}$

Com efeito, o vasto programa comemorativo incluía a publicação não só do foral de 1111 mas de todos os documentos responsáveis pela origem, evolução e consolidação do concelho de Coimbra até ao século XVI. Vice-Presidente, então, da Autarquia de Coimbra, promovi e dirigi este projecto ambicioso, com a assessoria de Joana Gouveia Loureiro,

1 Diga-se, a este propósito, que Coimbra recebeu o Prémio de Melhor Programação Cultural Autárquica 2011 atribuído ex aequo pela Sociedade Portuguesa de Autores em cerimónia solene, no Centro Cultural de Belém, no dia 28 de Fevereiro de 2012. 
cujo encargo foi entregue à especialista em História do Municipalismo, catedrática da Faculdade de Letras e investigadora do Centro de História da Sociedade e da Cultura da Universidade de Coimbra, Maria Helena da Cruz Coelho. Quase dois anos de intenso labor produziram o estudo a que a autora deu o título O Município de Coimbra. Monumentos Fundacionais. Por sua vez, a co-edição com a Imprensa da Universidade de Coimbra, superiormente dirigida por Delfim Leão, foi coordenada de forma exemplar por Maria João Padez de Castro e revela ser, no tempo actual das cibernéticas bibliotecas, um livro de grande beleza, de ímpar qualidade, de prestígio, que faz jus, no século XXI, “à famosa arte da imprimissão". A profundidade da investigação e densidade do texto são atenuadas pela mancha escrita em duas colunas, efeito favorável ao leitor, cujas vantagens já o homem medieval conhecia muito bem.

Com mais de duas centenas e meia de páginas, a obra apresenta-se marcadamente bicéfala. Com efeito, as primeiras 80 contextualizam os documentos em apreço, no reino de Portugal, e, em particular, no concelho de Coimbra desde os tempos romanos, tema recentemente aprofundado em obras de referência por Jorge de Alarcão, até ao século XVI. A $2^{\mathrm{a}}$ parte é constituída pelas "memórias escritas", ou seja, pela transcrição, estudo paleográfico, codicológico e diplomático, tradução, glossário e fac-símile de todos os documentos considerados fundadores de Coimbra/concelho, de 1085 a 1516, mais de 400 anos de história. É habitual estabelecer-se o termo a quo para os primórdios concelhios de Coimbra no ano de 1111 mas Maria Helena da Cruz Coelho quis deixar para lembrança, de todos nós conimbricenses, que antes de sermos condado já lutávamos pelo reconhecimento dos nossos costumes, privilégios e terras. Deste modo, o imperador da Hispânia, Afonso VI, vai ao encontro dos pedidos dos homens de Coimbra concedendo-lhes "com amor" um "documento de escritura de firmeza", datado de Toledo, 29 de Maio de 1085, que confirma em 22 de Abril de 1093. Se acrescentarmos a esta carta, os conhecidos antecedentes, de naturezas diversas, da outorga do foral de 1111, compreendemos, como escreve a Autora, que “...o foral não estava a dar origem a um concelho, mas apenas lhe aumentava os privilégios e liberdades, e consignava, de uma forma precisa e explícita, os seus direitos e deveres" (p. 23). Por ele vê-se Coimbra/concelho com uma sede urbanizada embora com terras de cultivo 
mesmo dentro das muralhas; quanto ao termo, esse era totalmente rural e, por isso, fonte abastecedora dos bens alimentares indispensáveis à cidade. No itinerário documental concelhio, a Autora detém-se, em seguida, nas posturas de 1145, as mais antigas até hoje conhecidas no reino de Portugal. Chegaram até nós em cópia de finais do século XII - inícios do XIII e são um paradigma do estilo de governação do rei D. Afonso Henriques que as legitima. Coimbra era um pólo de atracção e irradiação económico-comercial e industrial. A prosperidade ressalta das cláusulas maiores e menores do documento e a articulação de Coimbra com o restante território acentua-se com a outorga de D. Afonso Henriques, em 1179, de três forais às cidades de Santarém, Lisboa e Coimbra. A Autora disserta sobre este foral, e as suas repercussões na vida da cidade, com a autoridade de quem há muito o conhece e estuda (lembremos que o estudou e publicou por ocasião da celebração dos 800 anos, em 1979). "As memórias escritas", bem como o livro, encerram com o foral manuelino de 1516. O título "Antecedentes: um foral caro e litigioso" não só desperta o interesse do leitor como deixa antever que a abordagem é inovadora e traz a lume dados até aqui ignorados. À semelhança de muitos outros, o foral manuelino de Coimbra está há quase 500 anos no concelho a que pertence, isto é, está guardado, num belíssimo estado de conservação, como prova o fac-símile, no Arquivo Municipal, na Casa Municipal da Cultura. Surge, como é do conhecimento geral, na sequência da chamada Reforma dos Forais, requerida desde o século XV pelos povos, em Cortes, que consistiu numa remodelação das leis, ou melhor, na adaptação das normas gerais às locais. D. Manuel empreendeu, deste modo, a maior e mais profunda acção governativa desta natureza traduzida, por um lado, na mobilização de escrivães, correctores, rubricadores, legistas, inquiridores, oficiais locais e gerais e, por outro, na despesa exorbitante feita com a aquisição de largas centenas de peles, de um número incalculável de penas e de litros de tinta de escrever, castanha, vermelha, azul, entre outras. Não esquecer ainda os gastos com os selos regra geral de chumbo, na maioria desaparecidos, como acontece no nosso exemplar - com as encadernações de bom couro com ferragens de cobre, enfim, tudo em triplicado, pois eram feitos três exemplares de cada "livro": um para a Câmara, outro para o senhorio e outro para o arquivo régio da Torre do Tombo. 
Mas Coimbra, em particular, também despendeu forças e dinheiro para receber o seu foral. Factores distantes e outros próximos, dos quais merece destaque a discórdia entre o concelho e o Conde D. Pedro de Meneses, a propósito dos significativos rendimentos que este nobre possuía, e de que não desejava prescindir, explicam o que escrevemos. Sucederam-se confrontos, dentro e fora dos tribunais, usando as armas ofensivas e defensivas daqueles tempos, isto é, papéis e pergaminhos que em nenhum caso levantassem dúvidas. Compreensivelmente, o mal-estar instalava-se entre oficiais e rendeiros que cobravam os direitos da cidade. Coimbra apresentava, exibia, lia ou mandava ler os forais antigos, em particular o de 1179, de Afonso Henriques, e solicitava ao Rei o respeito pelos direitos e deveres há muito estabelecidos. O certo é que esta "guerra de diplomas" (parecendo antecipar as bella diplomatica do século XVII) provocou um atraso significativo na outorga do foral. Na verdade, Coimbra pedia ao rei, pelo menos desde 1505, a carta foraleira mas as respostas denunciavam cautela e prudência na redacção definitiva. Finalmente, com data de Lisboa, 4 de Agosto de 1516, o foral é outorgado. Todavia, só em 1517 vereadores, procuradores dos mesteres e outros oficiais tiveram acesso ao documento. A demora foi compensada, no entanto, pelo regozijo que o concelho de Coimbra experimentou ao verificar que tinham sido respeitadas as suas mais antigas e sagradas regalias.

O Município de Coimbra. Monumentos fundacionais é pela sua grandeza histórico-científica uma homenagem à cidade, às suas gentes e ao seu património que, por feliz coincidência, foi, igualmente, neste ano de 2013, inscrita na lista de Bens da Humanidade.

Concluo exprimindo a minha convicção de que as Câmaras Municipais, no que toca à sua história e ao seu património, não podem ficar pelo papel de receptores, antes devem chamar a si a responsabilidade de produzirem obras, pareceres, colóquios, rodeando-se para isso de especialistas, a fim de marcar a identidade colectiva local, valor único no contexto nacional e internacional.

\section{Maria José Azevedo Santos}

Universidade de Coimbra e Centro de História da Sociedade e da Cultura da Universidade de Coimbra mazevedo_santos@yahoo.com 